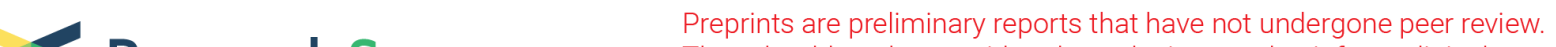 $\begin{array}{ll}\text { Research Square } & \begin{array}{l}\text { They should not be considered conclusive, used to inform clinical practice, } \\ \text { or referenced by the media as validated information. }\end{array}\end{array}$
}

\section{Pain in Veterans with COPD: Relationship with Physical Activity and Exercise Capacity}

Rebecca Raphaely

Massachusetts General Hospital

Maria Mongiardo

VA Boston Healthcare System

Rebekah L. Goldstein

VA Boston Healthcare System

Stephanie A. Robinson

Edith Nourse Rogers Memorial Veterans Hospital

\section{Emily S. Wan}

VA Boston Healthcare System

Marilyn Moy ( $\square$ marilyn.moy@va.gov )

VA Boston Healthcare System

\section{Research Article}

Keywords: Chronic Obstructive Pulmonary Disease (COPD), pain, physical activity (PA), exercise capacity, 6-minute walk test (6MWT), physical activity intervention

Posted Date: April 8th, 2021

DOI: https://doi.org/10.21203/rs.3.rs-380820/v1

License: (c) (1) This work is licensed under a Creative Commons Attribution 4.0 International License.

Read Full License

Version of Record: A version of this preprint was published at BMC Pulmonary Medicine on July 15th, 2021. See the published version at https://doi.org/10.1186/s12890-021-01601-8. 
Pain in Veterans with COPD: Relationship with Physical Activity and Exercise Capacity

2

3 Rebecca A. Raphaely MD ${ }^{1-4}$, Maria Mongiardo MPH ${ }^{1}$, Rebekah L. Goldstein MPH ${ }^{1}$, Stephanie A.

4 Robinson $\mathrm{PhD}^{1,5,6}$, Emily S. Wan $\mathrm{MD}^{1,4,7}$, Marilyn L Moy MD, MSc ${ }^{1,4}$

5

6 1. Pulmonary and Critical Care Medicine Section, VA Boston Healthcare System, Boston, MA

7 2. Department of Pulmonary \& Critical Care, Massachusetts General Hospital, Boston, MA

8 3. Department of Pulmonary \& Critical Care, Beth Israel Deaconess Medical Center, Boston, MA

9 4. Harvard Medical School, Boston, MA

10

5. Center for Healthcare Organization and Implementation Research, Edith Nourse Rogers Memorial Veterans Hospital, Bldg 70, 200 Springs Rd, Bedford, MA, USA, 01732

6. Pulmonary Division, Boston University School of Medicine, Boston, MA

14

15 Correspondence and requests for reprints should be addressed to

16 Marilyn L. Moy, MD, MSc

17 VA Boston Healthcare System

18 Pulmonary and Critical Care Section

191400 VFW Parkway, Mail Code 111P

20 West Roxbury, MA 02132

21 E-mail: marilyn.moy@,va.gov

22 
Abstract:

28 Background: Pain is a common but underappreciated symptom experienced by people with Chronic

29 Obstructive Pulmonary Disease (COPD). The relationships between pain and physical activity (PA) and exercise capacity are poorly understood.

31 Methods: This retrospective secondary analysis included three cohorts of Veterans with COPD and

32 objective measures of PA (daily step counts) and exercise capacity (6-minute walk test [6MWT] distance)

33 who participated in longitudinal studies evaluating PA. Pain was assessed using the Bodily Pain (BP)

34 domain of the Veterans RAND-36. In two cohorts, participants were randomly assigned to a web-based,

35 pedometer-mediated PA intervention which has previously been demonstrated to improve PA.

36 Results: Three-hundred and seventy-three (373) unique study participants were included in this analysis.

37 Eighty-three percent $(\mathrm{n}=311)$ of the population reported at least mild pain and/or at least a little bit of

38 interference due to pain at baseline. Cross-sectionally, greater BP was associated with lower 6MWT

39 distance $(\beta=0.51 ; 95 \%$ CI $0.20,0.82 ; p=0.0013)$. Longitudinally, worsening BP was associated with a

40 decline in $6 \mathrm{MWT}$ distance $(\beta=0.30 ; 95 \%$ CI $0.03,0.58 ; \mathrm{p}=0.0312)$. There was no association between

41 baseline BP and baseline daily step counts, baseline BP and change in PA, or change in BP and change in

42 PA. Compared to usual care, our PA intervention improved BP scores $(\beta=6.17 ; 95 \%$ CI $1.84,10.45$;

$43 \mathrm{p}=0.0054)$. BP scores did not affect the impact of the intervention on daily step counts.

44 Conclusion: Pain is highly prevalent and significantly associated with lower exercise capacity among

45 Veterans with COPD. Worsening pain co-occurred with decline in exercise capacity but not PA. Our 46 intervention reduced pain, although pain did not affect the impact of the intervention on PA.

48 Keywords: Chronic Obstructive Pulmonary Disease (COPD), pain, physical activity (PA), exercise 49 capacity, 6-minute walk test (6MWT), physical activity intervention 
52 (COPD) experience a substantial physical and psychological symptom burden. ${ }^{1-3}$ Although dyspnea is the most commonly reported symptom, recent studies suggests that pain is also highly prevalent but less wellrecognized in this population. ${ }^{2-4}$ Among patients with COPD, the pooled prevalence of pain is estimated to be $66 \%$ with a range of $45-96 \%$, depending on the sample size, study design, and definition of pain used. ${ }^{4-12}$ Compared to a population with chronic medical conditions matched for gender, age, and comorbidities, a significantly higher percentage of people with COPD have a diagnosis of pain. ${ }^{11-12}$ Epidemiological studies also suggest that people with COPD have higher rates of chronic opiate and nonopiate pain medication prescription compared to age and gender match controls, supporting the assertion that pain is more prevalent in this population..$^{12-13}$

Promotion of exercise and physical activity (PA) is the standard of care in persons with COPD. ${ }^{14-}$

$62{ }^{16}$ In the COPD population, greater PA is associated with improved health related quality of life (HRQL),

63 reduced risk of acute exacerbations and hospitalizations, and greater survival, independent of lung

64 function. ${ }^{14-20}$ Three cross-sectional studies, and one study with short-term follow-up, have demonstrated 65 an association between pain and decreased levels of PA (self-report, surveys, standing time) and exercise 66 capacity, as measured by the 6-minute walk test (6MWT), among patients with COPD. ${ }^{21-24}$ There are no 67 studies to date, however, evaluating these relationships with direct measures of PA in persons with COPD ready to engage in PA. In addition, understanding the prevalence of pain in this population and studying how technology-based PA interventions impact pain are critical to effectively implement the GOLD recommendation to promote PA in all persons with stable COPD. ${ }^{14}$

We have previously studied Veterans with COPD who self-selected to enroll in research studies

72 using accelerometers and pedometers to directly measure PA. ${ }^{18,25-27}$ In one observational cohort study, we 73 measured daily step counts over 14 days at two time points, 3 months apart, and evaluated the association 74 between PA and 6MWT, HRQL, and acute exacerbation. ${ }^{18,25}$ In two separate studies, we demonstrated 
75 the efficacy of a web-based, pedometer-mediated intervention to increase PA. ${ }^{26,27}$ In this retrospective

76 secondary analysis, we combined these three well-characterized cohorts in order to (1) understand the

77 prevalence of pain in persons with COPD who are ready to engage in PA, (2) evaluate the cross-sectional

78 and longitudinal associations between pain and exercise capacity (6WMT distance) and PA (directly

79 measured daily step counts), (3) examine the impact of our web-based pedometer-mediated PA

80 intervention on pain, and (4) assess the impact of pain on the response to our PA intervention.

81

\section{Materials and Methods}

83 Study Participants:

84 The study population consisted of three cohorts of Veterans with COPD $(n=375)$ who volunteered to

85 participate in PA studies. Cohort $1(n=163)$ was an observational study including people recruited from pulmonary clinics at the Veterans Affairs (VA) Boston Healthcare System between 2009-2011. ${ }^{18,25}$ Cohort

$872(\mathrm{n}=104)$ included Veterans enrolled from pulmonary clinics at VA Boston from 2012-2015 for a randomized controlled trial (RCT) (NCT01772082) comparing a web-based, pedometer-mediated PA intervention to pedometer alone. ${ }^{26}$ Cohort $3(n=108)$ included people enrolled from VA Boston from 20152019 for a RCT in which participants were assigned to the technology-based PA intervention or usual care

91 (NCT02099799). ${ }^{27}$ People randomized to the intervention arm participated in the same web-based,

92 pedometer-mediated intervention (Table 1). All protocols were approved by the VA Boston Healthcare

93 System Institutional Review Board on Human Subjects Research (Protocol \#1961, Protocol \#2328, Protocol

94 \#2791), and written informed consent was obtained from participants. In cases where study participants

95 enrolled in more than one trial, only the most recent trial data were used so that all study participants are

96 unique. Of note, participants in cohorts 1 and 2 used the Omron HJ-720 ITC pedometer while those in

97 cohort 3 used the FitBit Zip pedometer because the Omron HJ-720 ITC was discontinued. The accuracy of

98 both pedometers in people with COPD has been confirmed in previous studies. ${ }^{31,32}$ 
Analyses of all data are approved by VA Boston IRB \#2999 Pulmonary Research Data Repository.

100 Either participants provided written consent, or the IRB approved a waiver of HIPAA authorization for use

101 of repository data. Study was carried out in accordance with the Declaration of Helsinki.

Table 1. Characteristics of three cohorts of Veterans with COPD and an interest in physical activity.

\begin{tabular}{|c|c|c|c|}
\hline & Cohort $1^{18,25}$ & Cohort $2^{26}$ & Cohort $3^{27}$ \\
\hline Study participants & 163 & 108 & 104 \\
\hline Study design & $\begin{array}{l}\text { Observational } \\
\text { Cohort }\end{array}$ & \multicolumn{2}{|c|}{ Randomized Controlled Trial } \\
\hline Study Sites & VA Boston & VA Boston & $\begin{array}{l}\text { VA Boston, } \\
\text { VA Birmingham* }\end{array}$ \\
\hline Recruitment period & 2009-2011 & $2012-2015$ & 2015-2019 \\
\hline Study duration & 3 months & 3 months & 6 months \\
\hline Intervention group & NA & \multicolumn{2}{|c|}{$\begin{array}{l}\text { Web-based pedometer-mediated physical activity } \\
\text { program }\end{array}$} \\
\hline Comparison group & NA & Pedometer & Usual care \\
\hline Pedometer type & Omron HJ-720 ITC & Omron HJ-720 ITC & FitBit Zip \\
\hline $\begin{array}{r}\text { Valid pedometer wear days } \\
\text { for step counts }\end{array}$ & $\begin{array}{l}\geq 200 \text { steps and } \geq 8 \\
\text { hours of wear time }\end{array}$ & $\begin{array}{l}\geq 100 \text { steps and } \geq 8 \\
\text { hours of wear time }\end{array}$ & $\geq 200$ steps \\
\hline $\begin{array}{r}\text { Minimum days assess for } \\
\text { step counts }\end{array}$ & $\geq 5$ & $\geq 5$ & $\geq 5$ \\
\hline
\end{tabular}

Inclusion/Exclusion Criteria:

107 Study participants were $\geq 40$ years-old with a diagnosis of COPD based on a smoking history $\geq 10$ pack-

108 years and a forced expiratory volume in the first second $\left(\mathrm{FEV}_{1}\right)$ to forced expiratory capacity $(\mathrm{FVC})$ ratio

109 of $\leq 0.70$ or emphysema on chest computed tomography. Exclusion criteria included unstable

110 cardiovascular disease, acute exacerbation of COPD $<4$ weeks prior to enrollment, and inability to

111 ambulate. 
113 Intervention: Study participants in cohort 2 and cohort 3 were assigned to the same PA intervention

114 consisting of a pedometer plus a website that provides goal setting, feedback, motivational messages,

115 educational content, and social support. This intervention has previously been shown to increase PA and

116 improve HRQL at three and six months. ${ }^{26,27}$ To evaluate the impact of the PA intervention on pain, study

117 participants were divided into groups based on participation in the PA intervention. Group 1, those

118 assigned to the intervention $(n=111)$, consisted of participants in cohort $2(n=57)$ and cohort $3(n=54)$.

119 Group 2, those who did not use the intervention $(n=264)$, consisted of participants in cohort $1(n=163)$,

120 cohort $2(n=47)$, and cohort $3(n=54)$. Among the participants in group 2, those from cohort 1 and cohort

$1213(n=217)$ received usual care while those from cohort $2(n=47)$ used a pedometer throughout the study

122 period.

123

124 Outcomes: Participants completed spirometry, 6MWT, assessment of PA as daily step counts, Veterans

125 RAND-36 Item Health Survey (VR-36), modified Medical Research Council dyspnea scale (mMRC), and

126 self-reported demographics and medical history at the time of enrollment and at 3-months follow up.

127

128 Pain: Pain was assessed using the bodily pain (BP) domain of the VR-36 questionnaire. ${ }^{28-29}$ The BP

129 domain includes two questions assessing (1) pain intensity and (2) pain interference, over the preceding 4

130 weeks. Responses were evaluated using a standardized composite scoring system with scores ranging

131 from 0 to $100 .^{29}$ A score of ' 100 ' represents no pain while a score of '0' represents very severe pain

132 causing extreme interference with activities. The minimal clinically important difference (MCID) for the

133 BP domain was extrapolated from a COPD population evaluated with Short Form-36 which uses the same

134 two questions to assess pain severity and interference..$^{30}$ The MCID for a small improvement in pain

135 corresponds to a 10-point increase in the BP score, a moderate improvement corresponds to a 20-point

136 increase, and a large improvement correspond to a 30-point increase..$^{30}$ 
Physical Activity: Physical activity was measured by average daily step counts assessed objectively using pedometers: Omron HJ-720 ITC pedometer (cohort 1 and 2) and Fitbit Zip (cohort 3). We have

140 previously demonstrated that pedometers can accurately capture daily step counts among Veterans with COPD. ${ }^{31,32}$

Criteria for valid wear days are detailed in Table 1. All participants in both groups were blinded to step144 count feedback during a 7-day baseline collection period prior to randomization using an opaque sticker 145 covering the pedometer face (preventing feedback of daily step counts). After the baseline collection 146 period, study participants were not blinded to step-count data. Group 1 participants had access to 147 pedometers throughout the study. Monitoring of group 2 participants varied by study. Participants from 148 cohort 2 had access to an Omron pedometer throughout the study and were not blinded to step counts 149 after initial baseline data collection. Participants from cohort 3 had access to the study pedometer only 150 during the baseline collection period and for 14-days after the 3-month study visit. The MCID for daily 151 step counts in persons with COPD ranges from 350-1100 steps/day. ${ }^{33,34}$

152

153 Exercise Capacity: Exercise capacity was assessed with maximal distance walked on the 6MWT in 154 accordance with the American Thoracic Society/European Respiratory Society (ATS/ERS) guidelines, 155 without a practice walk. ${ }^{35}$ In this assessment, patients determined the exercise intensity and speed, were 156 allowed to rest, and used supplemental oxygen, if prescribed for activity. The MCID for 6MWT distance 157 is $30-54-$ meters. ${ }^{36,37}$

159 Pulmonary Function: Spirometry was performed at enrollment according to ATS guidelines. ${ }^{38} \mathrm{FEV}_{1}$ 160 percent predicted was calculated according to Hankinson's references. ${ }^{39}$ 

range from 0-4 with higher scores representing more severe dyspnea. ${ }^{40}$ The MCID has been reported to be one unit. ${ }^{41}$ Dyspnea was dichotomized $(\leq 2$ or $>3)$ for analysis.

\section{Statistical Analysis:}

167 Of the 375 study participants in the combined cohorts, two people were excluded because of incomplete 168 pain assessment at enrollment. Summary statistics are presented as means \pm SD for continuous variables 169 and frequencies for categorical or ordinal variables. Generalized linear regression models (PROC GLM) 170 were implemented to explore cross-sectional and longitudinal relationships between baseline BP scores, 171 6MWT distance, and daily step counts. Generalized linear regression models were also used to test the 172 association between the change in BP scores, change in 6MWT distance, and change in daily step counts. 173 Change in BP was evaluated as both a continuous and dichotomous variable based on an the MCID.

174 Multivariable models were adjusted for age, gender, percent predicted $\mathrm{FEV}_{1}$, body mass index (BMI), 175 dyspnea (mMRC score), and cohort. These covariates were selected based on known associations with the 176 outcomes and in order to adjust for possible differences between cohorts. Covariates were evaluated for 177 collinearity prior to inclusion. Models evaluating change in 6MWT distance and change in daily step 178 counts were also adjusted for group and baseline 6MWT distance and daily step counts when indicated. 179 Season of enrollment was included as a covariate for models with daily step counts as the outcome given established association between season and step counts. Differences between groups were evaluated with unpaired t-tests or chi-square tests. The impact of our PA intervention on BP score was evaluated using a generalized linear regression model adjusting for age,

184 percent predicted $\mathrm{FEV}_{1}, \mathrm{BMI}$, dyspnea, and cohort. Finally, given our previous results demonstrating that 185 our PA intervention is associated with a significant increase in daily step counts, ${ }^{26,27}$ we evaluated pain 186 as an effect modifier for the impact of the PA intervention on daily step counts using an interaction term 187 (group*BP score). All analyses were performed in SAS software version 9.4 (Cary, NC, USA) 
189 Results

190 Prevalence of Pain

191 For the combined cohort of Veterans interested in engaging in PA, 98\% of participants were male with an

192 average age of $70.5 \pm 8.3$ years, percent predicted $\mathrm{FEV}_{1}$ of $59.3 \pm 21.1$, and $\mathrm{BMI}$ of $29.5 \pm 5.9 \mathrm{~kg} / \mathrm{m}^{2}$.

193 Baseline average 6MWT distance was 375.8 \pm 96.0 meters and daily step counts were 3,167 $\pm 2,364$

194 steps/day. The range and distribution of pain scores are shown in Figure 1 with a score of 100 denoting

195 no pain and a score of 0 indicating very severe pain causing extreme interference with activity. Eighty-

196 three percent of the participants (311/373) reported at least mild pain and/or at least a little bit of

197 interference due to pain at enrollment, with the average BP score of $60.24 \pm 26.11$ points.

198

$199 \quad$ Figure 1: Distribution of bodily pain scores.

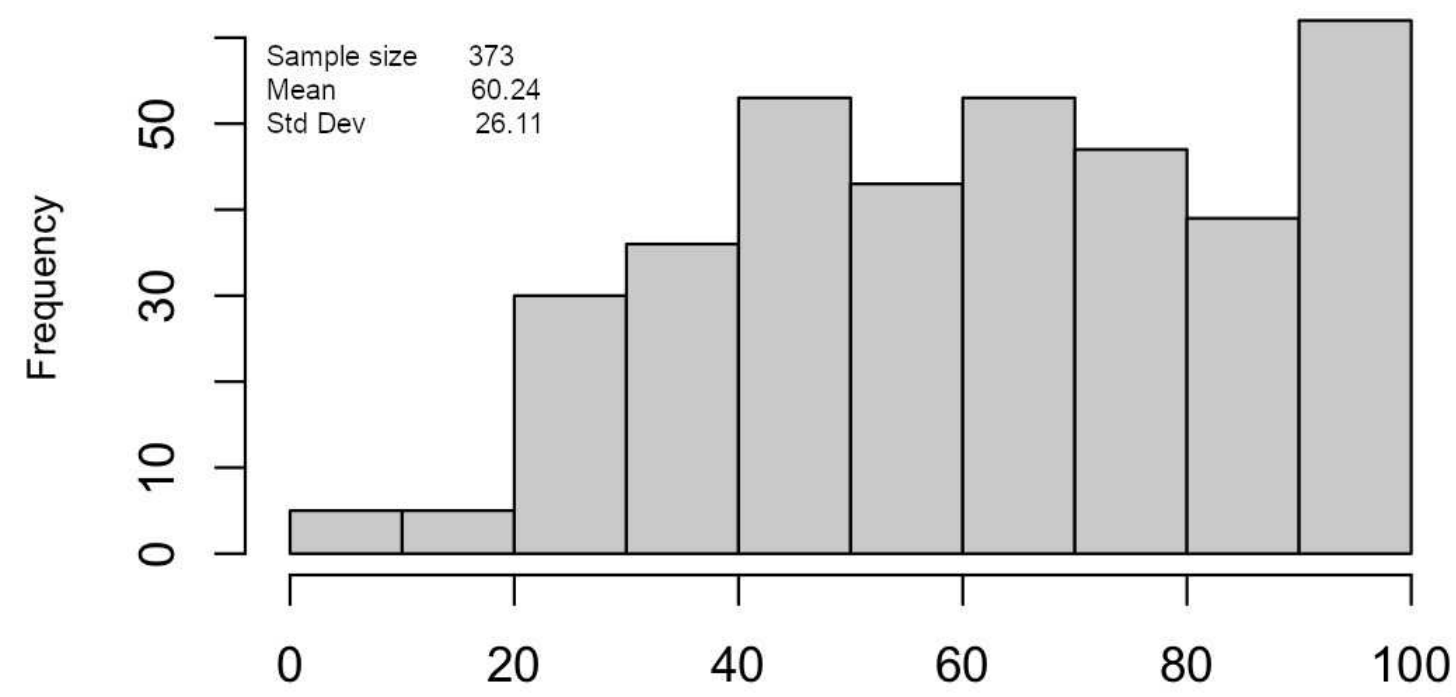

201 Caption: Histogram demonstrating the distribution of bodily pain scores evaluated with the VR36 survey

202 and assessing symptoms in the four weeks prior to study enrollment. A pain score of ' 100 ' ( $\mathrm{n}=62$ ) 
corresponds to no pain while a score of ' 0 ' $(\mathrm{n}=4)$ indicates very severe pain causing extreme interference

204 with daily activities.

205

Cross-Sectional Relationships Between Pain, 6MWT Distance, and Daily Step Counts

207 At baseline, higher BP scores (indicative of less pain severity and interference) was positively associated

208 with higher 6MWT distance. In this model, a 10-point increase in BP score (less pain) was associated

209 with a 5.1-meter increase in 6MWT distance $(\mathrm{p}=0.0013)$ (Table 2, Figure 2A). Accordingly, a 58-point

210 difference in BP score would achieve the MCID in 6MWT distance ( $\geq 30$ meters). ${ }^{36,37}$ There was no

211 significant relationship between baseline BP score and daily step counts.

212

213 Table 2: Relationship between pain and physical activity and exercise capacity.

\begin{tabular}{|c|c|c|c|}
\hline Outcome & Predictor & $\begin{array}{c}\text { Beta Coefficient } \\
\text { (95\% Confidence Interval) }\end{array}$ & P-value \\
\hline Baseline steps & Baseline pain & $5.85(-2.67,14.37)$ & 0.1178 \\
Change in steps & Baseline pain & $3.05(-4.16,10.25)$ & 0.4061 \\
Change in steps & Change in pain & $3.11(-6.10,12.31)$ & 0.5065 \\
\hline Baseline 6MWT & Baseline pain & $0.51(0.20,0.82)$ & 0.0013 \\
Change in 6MWT & Baseline pain & $-0.08(-0.30,0.14)$ & 0.4617 \\
Change in 6MWT & Change in pain & $0.30(0.03,0.58)$ & 0.0312 \\
\hline
\end{tabular}

Caption. Generalized linear regression models evaluating relationships between bodily pain (BP) score,

217 distance. 
225 Figure 2A, 2B: Relationships between pain and exercise capacity cross-sectionally (2A) and

226 longitudinally (2B).
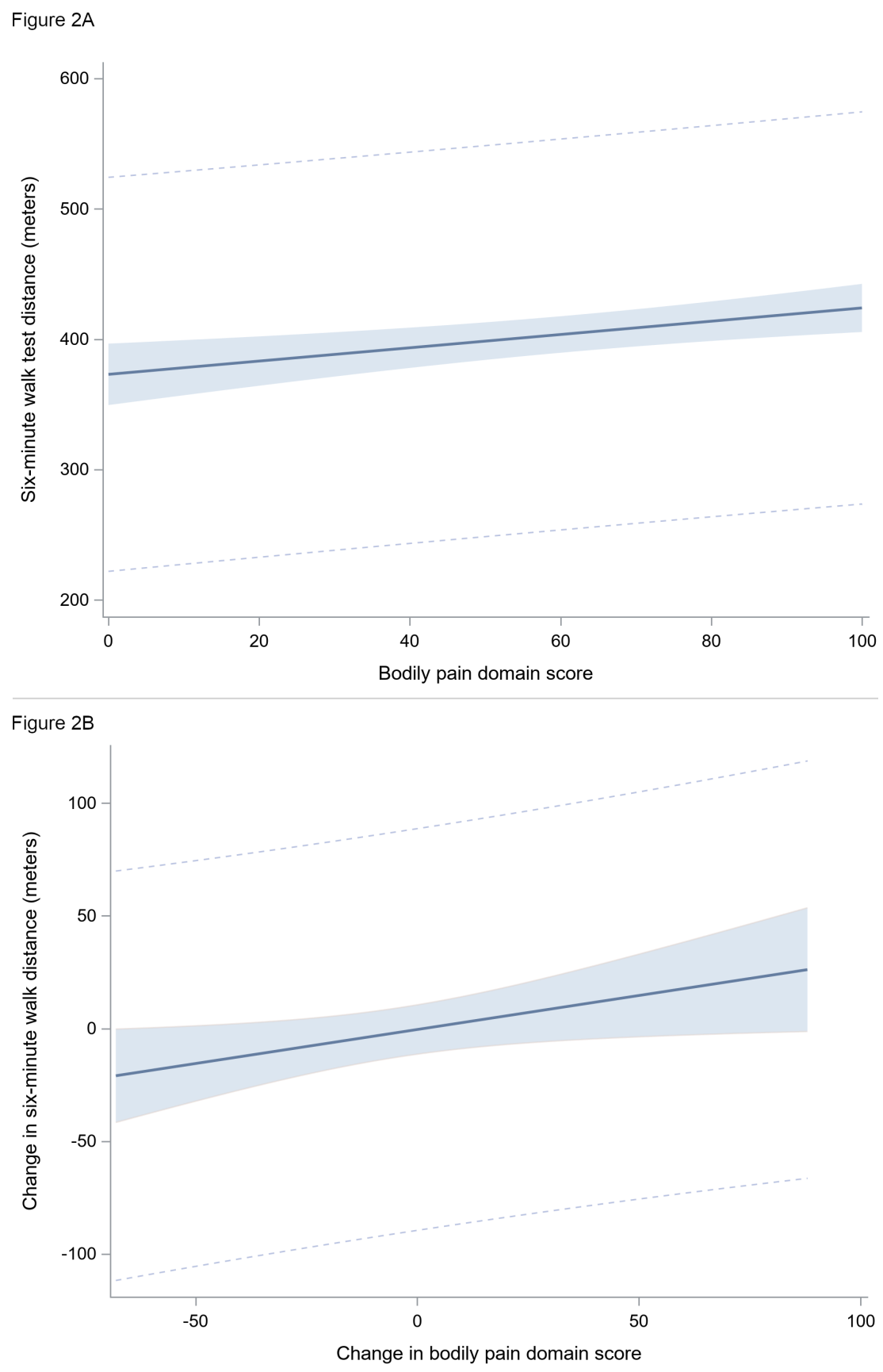

228 Caption: Generalized multivariate linear regression models with 95\% confidence interval adjusted for 229 BMI, percent predicted FEV1, and cohort. A bodily pain score of '100' represents no pain while a score of ' 0 ' represents severe pain causing extreme interference. A change in pain score $>0$ indicates improved 
pain. Figure 2A represents results of a model evaluating the cross-sectional relationship between bodily

232 pain score and 6MWT distance both measured at baseline. Figure 2B represents results of a model

233 evaluating the longitudinal relationship between the change in BP and 6MWT.

Longitudinal Relationships Between Pain, 6MWT Distance, and Daily Step Counts

At three months, 87 (23\%) study participants were lost to follow-up. Compared to people who participated in a study for 3 months $(51.41 \pm 24.59)$, those lost to follow-up had worse pain $(62.93 \pm 26.00)$ $(p=0.0003)$ and were more likely to be from group $2(n=79,30 \%)$ than group $1(n=8,7 \%, p<0.0001)$.

Age, BMI, mMRC dyspnea scale, and percent predicted $\mathrm{FEV}_{1}$ did not significantly differ between those who completed the study and those lost to follow-up.

Among the participants with complete data, baseline BP score did not predict change in either 6WMT distance or daily step counts, adjusting for exposure to the PA intervention. However, an improvement in BP score was positively and significantly associated with an increased 6MWT distance over the 3-months period in the total population when adjusting for group. A 10-point improvement in BP score was associated with a 3.0-meter increase in 6WMT distance over 3 months $(\mathrm{p}=0.0312)$ (Table 2, Figure 2B).

Demographics and baseline BP score, daily step counts, and 6MWT distance did not significantly differ between the two groups (Table 3). Among the 283 participants who had a complete pain assessment at three months, use of the PA intervention was associated with a significant decrease in the BP score, 252 compared to the group who received usual care or pedometer. Participants in group 1, on average, had a

253 6.17-point increase in BP score (corresponding to reduced pain severity and/or interference) compared to 254 those in group 2 (Table 2). Evaluating BP score as a dichotomous variable for a small improvement 255 (change $\geq 10$ points versus $<10$ points) $32 \%$ ( $n=35$ ) of group 1 participants experienced at least a small 256 improvement of pain while only $15 \%(n=38)$ of group 2 participants experienced the same benefit. 
257 Accordingly, participation in the PA intervention was associated with 2.71 times the odds of having at

258 least a small improvement in BP score over 3 months (OR 2.71, 95\% CI 1.60, 4.60; $\mathrm{p}=0.0002) .{ }^{30}$

259 Table 3. Characteristics of patients with COPD who volunteered for PA studies.

\begin{tabular}{|c|c|c|c|c|}
\hline & $\begin{array}{c}\text { Group } 1 \\
\text { Exposed to web- } \\
\text { based PA } \\
\text { Intervention }\end{array}$ & $\begin{array}{c}\text { Group } 2 \\
\text { Unexposed to } \\
\text { web-based PA } \\
\text { Intervention }\end{array}$ & $\begin{array}{l}\text { Combined } \\
\text { Cohorts }\end{array}$ & $P$-value \\
\hline $\mathbf{N}$ & 111 & 262 & 373 & \\
\hline Age- yr (SD) & $69.22(8.36)$ & $71.02(8.23)$ & $70.49(8.30)$ & 0.0545 \\
\hline Male Gender-no. (\%) & $108(97)$ & $256(98)$ & $364(98)$ & 0.8123 \\
\hline White Race-no. (\%) & $103(93)$ & $243(93)$ & $346(93)$ & 0.8984 \\
\hline Married no. (\%) & $52(47)$ & $129(49)$ & $181(49)$ & 0.5047 \\
\hline $\mathrm{BMI}-\mathrm{kg} / \mathrm{m}^{2}(\mathrm{SD})$ & $30.30(5.88)$ & $29.15(5.93)$ & $29.49(5.93)$ & 0.0871 \\
\hline Pack-years (SD) $(n=369)$ & $57.70(35.00)$ & $64.06(39.11)$ & $62.15(37.98)$ & 0.1403 \\
\hline $\begin{array}{l}\text { FEV } 1 \% \text { predicted-avg }(\mathrm{SD}) \\
(\mathrm{n}=367)\end{array}$ & $62.28(21.22)$ & $58.09(21.01)$ & $59.32(21.13)$ & 0.0833 \\
\hline $\begin{array}{l}\text { Supplemental Oxygen Use- } \\
\text { no.(\%) }\end{array}$ & $22(20)$ & $60(23)$ & $82(22)$ & 0.5341 \\
\hline $\begin{array}{l}\text { MMRC-no. (\%) } \\
0-2 \\
3-4\end{array}$ & $\begin{array}{l}74(67) \\
37(33)\end{array}$ & $\begin{array}{l}156(60) \\
106(40)\end{array}$ & $\begin{array}{l}230(62) \\
143(38)\end{array}$ & 0.1957 \\
\hline $\begin{array}{l}\text { 6MWT Distance-meters (SD) } \\
\text { Baseline } \\
3 \text { months }(\mathrm{n}=283) \\
\Delta 6 \text { MWT }(\mathrm{n}=283)\end{array}$ & $\begin{array}{c}380.54(89.61) \\
385.50(95.65) \\
0.47(47.61)\end{array}$ & $\begin{array}{c}373.75(98.57) \\
377.70(102.60) \\
0.17(44.33)\end{array}$ & $\begin{array}{c}375.77(95.93) \\
380.48(100.06) \\
0.28(45.44)\end{array}$ & $\begin{array}{l}0.5327 \\
0.5298 \\
0.9576\end{array}$ \\
\hline $\begin{array}{l}\text { Daily Step Counts-steps (SD) } \\
\text { Baseline } \\
3 \text { months }(\mathrm{n}=275) \\
\Delta \text { Steps }(\mathrm{n}=275)\end{array}$ & $\begin{array}{c}3296(2361) \\
4024(2479) \\
678(1857)\end{array}$ & $\begin{array}{l}3112(2367) \\
3054(2302) \\
-180(1470)\end{array}$ & $\begin{array}{c}3167(2364) \\
3403(2408) \\
128.54(1669)\end{array}$ & $\begin{array}{c}0.4927 \\
0.0013 * \\
0.0001 *\end{array}$ \\
\hline $\begin{array}{l}\text { Bodily Pain-avg (SD) } \\
\text { Baseline } \\
3 \text { months }(\mathrm{n}=284) \\
\Delta \text { Bodily Pain }(\mathrm{n}=284)\end{array}$ & $\begin{array}{c}61.11(25.14) \\
65.73(22.99) \\
3.12(22.37)\end{array}$ & $\begin{array}{l}59.87(26.54) \\
60.47(24.63) \\
-2.64(18.07)\end{array}$ & $\begin{array}{l}60.24(26.11) \\
62.36(24.15) \\
-0.57(19.88)\end{array}$ & $\begin{array}{c}0.6770 \\
0.0783 \\
0.0273 *\end{array}$ \\
\hline
\end{tabular}

Caption. Patients are divided into two groups based on exposure to web-based, pedometer mediated PA

262 intervention. Group 1 consists of study participants exposed to PA intervention while Group 2 consists of

263 study participants who were not randomized to undergo PA intervention. * Indicates significant p-value

$264<0.05$.

265

266

Baseline Pain and Response to PA Intervention 
As previously published in two separate RCTs, participants assigned to our PA intervention experienced a significantly greater improvement in daily step counts compared to those who did not use the intervention. ${ }^{18,25-27}$ In this retrospective analysis of combined datasets, participants in group 1 improved their daily step counts compared to those in group 2 ( $\beta=705$ steps/day, 95\% CI 261, 1,148; $p=0.0020$ ). Baseline BP score, however, was not a significant predictor for change in daily step counts $(\beta=3.05 \pm 3.66$; 95\% CI $-4.16,10.25, \mathrm{p}=0.4061$ ) (Table 2). Furthermore, baseline BP score did not significantly modify the impact of the PA intervention on daily step counts as examined using an interaction term $(\beta=5.91 ; 95 \%$ CI $-6.15,17.98 ; \mathrm{p}=0.3353)$.

\section{Discussion}

This secondary analysis of persons with COPD who volunteered to participate in PA studies shows that pain is not only highly prevalent in this population, but it is also associated with reduced exercise capacity. Cross-sectionally, lower composite pain scores (worse pain), incorporating pain severity and interference, are associated with lower 6MWT distances, and worsening pain over time is associated with a decline in 6MWT distance. Baseline pain was not, however, significantly associated with baseline step counts, and pain did not modify the impact of a technology-based PA program to increase daily step counts. Importantly, our technology-based PA program reduced pain in persons with COPD.

Our results support previous studies which suggest that pain is highly prevalent among people with COPD and build on findings that pain may be negatively associated with activity and exercise. ${ }^{21-24}$ The prevalence of pain $(83 \%)$ in our population, was at the upper limit of that reported in the literature, $45-85 \% .{ }^{4}$ Furthermore, the average BP score in our population $(60.24 \pm 26.11)$ was lower than the average score in a non-VA population with chronic medical and psychiatric conditions (70.77 \pm 25.46$)$ suggesting greater pain intensity and interference in our COPD study population. ${ }^{42}$ In fact, $35 \%$ of participants had a BP score lower than one SD from the general population mean ( $<45$ points), highlighting that pain is common and severe even among those interested in PA. Like previous studies our results demonstrates an 
association between pain and exercise capacity, however, in contrast to the literature, our work does not

294 support an association between pain and PA. This is likely related to our larger sample size and the use of 295 directly rather than indirectly measured PA.

Our work advances the literature by assessing the longitudinal associations between pain and

297 directly observed PA in patients with COPD and evaluating the relationship between pain and a

298 technology-based PA intervention. To date, one prospective case-control study, by Lee et al, has

299 evaluated the impact of an exercise program on pain. ${ }^{24}$ In that study, among people with COPD and

300 chronic pain, a traditional PR program was not associated with change in pain. In contrast, our study

301 demonstrates that a technology-based PA program can reduce pain, underscoring that pain is not

302 necessarily a reason to refrain from PA and exercise counseling in persons with COPD. ${ }^{43,44}$ The study by

303 Lee et al further demonstrated that the response to PR, measured by 6MWT distance, did not vary based

304 on the presence of pain. ${ }^{24}$ Although our results indicate that pain does not modify the impact of a technology-based intervention to increase PA (the primary outcome for that intervention), although pain was significantly associated with 6MWT. Our results suggest that people with pain benefit from exercise

307 interventions. These findings are important in the COVID-19 era since technology interventions are needed to support COPD patients who must remain physically active while socially distancing. They also support that pain should be routinely evaluated and treated as part of exercise counseling for patients with $\mathrm{COPD}^{43}$ observe an association between pain and directly measured PA in our relatively large study population.

313 There are several possible explanations. In this retrospective study, we lacked data regarding use of 314 analgesic pain medications and other therapeutic interventions, including massage and heating/cooling 315 pads. It is possible that patients with pain were treating symptoms at home thus mitigating the impact of 316 pain on daily step counts but not 6MWT distance which was assessed episodically in the clinic.

317 Differences in measurement techniques for exercise capacity and PA may also explain the differential 318 impact of pain. Exercise capacity is evaluated via the 6MWT performed under standardized conditions, 
while daily step counts are measured with a pedometer worn throughout the day in the patient's home where environmental and psychosocial factors may mitigate the impact of pain. ${ }^{45-48}$

Strengths of our study include the large sample size and use of well-described cohorts with rigorously assessed, repeated, and objective measures of PA and exercise capacity. Limitations are inherent to the study design of a retrospective secondary analysis. Based on the available data, we assessed pain using the VR-36 survey. Although the domain evaluates both pain severity and interference,

325 a more comprehensive and detailed survey that has previously been validated in people with COPD, like

326 the Brief Pain Inventory, would likely be helpful in assessing pain with more granularity. ${ }^{49}$ Our

327 population consisted of older, Caucasian men recruited from a single geographical location, limiting generalizability and underscoring the need for research including a more racially diverse population especially given that the perception of pain may be mediated through gender and cultural perspectives. Finally, our study design, in which we recruited participants interested in participating in PA programs, selected for a population with relatively tolerable pain and significant motivation to exercise. This is also supported by the differential loss to follow up based on the observation that participants with greater pain were less likely to complete the study. This may suggest that our results cannot necessarily be extrapolated to people with more severe or debilitating pain who are likely minimally active. Despite this, the relatively low rate of attrition in the intervention group compared to the usual care/pedometer group (7\% vs 30\%) combined with significant improvement in pain observed in the intervention group suggest that participation in a PA program is overall beneficial to those with pain.

\section{Conclusions} exercise capacity among patients with COPD interested in engaging in PA. A technology-based PA

342 intervention may be a nonpharmacological treatment of pain. Identifying and treating pain should be 343 routine parts of exercise counseling in COPD. 
$346 \quad$ List of Abbreviations:

347 ATS: American Thoracic Society

348 BMI: Body mass index

349 BP: Bodily pain

350 CI: Confidence interval

351 COPD: Chronic Obstructive Pulmonary Disease

352 ERS: European Respiratory Society

$353 \quad \mathrm{FEV}_{1}:$ Forced expiratory volume in the first second

354 FVC: Forced expiratory capacity

355 GOLD: Global Initiative for Obstructive Lung Disease

356 HRQL: Health related quality of life

357 MCID: Minimally clinically important difference

358 mMRC: Modified Medical Research Council

359 PA: Physical activity

360 PR: Pulmonary rehabilitation

361 RCT: Randomized controlled trial

362 SD: standard deviation

363 VA: Veteran's Affairs

364 VR-36: Veteran's RAND 36 Item Health Survey

365 6MWT: 6-minute walk test

366

367

368

369 


\section{Declarations:}

371 Ethics Approval and Consent to Participate: This retrospective secondary analysis utilized deidentified

372 data from human subjects. Analyses of all data are approved by VA Boston IRB \#2999 Pulmonary

373 Research Data Repository. Either participants provided written consent, or the IRB approved a waiver of

374 HIPAA authorization for use of repository data. Study was carried out in accordance with the Declaration 375 of Helsinki.

376

377 Consent for Publication: Not applicable.

379 Availability of Data and Materials: The datasets generated and/or analyzed during the current study are 380 not publicly available according to rules of the Veterans Health Administration but are available from the 381 corresponding author upon reasonable written request and approval by the designated Privacy Officer and 382 Information Security Officer.

384 Competing Interests: The authors declare that they have no competing interests.

386 Funding: This study was supported by the United States Department of Veterans Affairs Rehabilitation 387 Research and Development Service [Career Development Awards 1 and 2, F6847W (Moy); CDA2 IK2RX002165 (Wan); Merit Award O1150-R (Moy)]. Dr. Robinson is supported by the National Heart, Lung, and Blood Institute K12HHL138049. The funders had no role in study design, data collection, and analysis, decision to publish, or preparation of the manuscript.

392 Author Contributions: RAR, MM, RLG, and MLM had full access to all of the data in the study and take 393 responsibility for the integrity of the data and the accuracy of the data analysis. RAR and MLM 394 contributed to study design, data analysis and interpretation, and the writing of the manuscript. RLG and 395 MM contributed to data analysis. SAR and ESW contributed to data analysis and interpretation 
396 Acknowledgements: Not applicable. 


\section{References}

1. Blinderman CD, Homel P, Billings JA, Tennstedt S, Portenoy RK. Symptom distress and quality of life in patients with advanced chronic obstructive pulmonary disease. J Pain Symptom Manage. 2009;38(1):115-123.

2. Wysham NG, Cox CE, Wolf SP, Kamal AH. Symptom burden of chronic lung disease compared with lung cancer at time of referral for palliative care consultation. Ann Am Thorac Soc. 2015;12(9):1294-301.

3. Joshi M, Joshi A, Bartter T. Symptom burden in chronic obstructive pulmonary disease and cancer. Curr Opin Pulm Med. 2012;18(2):97-103.

4. Lee AL, Harrison SL, Goldstein RS, Brooks D. Pain and its clinical associations in individuals with COPD: a systematic review. Chest. 2015;147(5):1246-1258.

5. Lohne V, Heer HC, Andersen M, Miaskowski C, Kongerud J, Rustøen T. Qualitative study of pain of patients with chronic obstructive pulmonary disease. Heart Lung. 2010;39(3):226-34.

6. Borge CR, Wahl AK, Moum T. Pain and quality of life with chronic obstructive pulmonary disease. Heart Lung. 2011;40(3):e90-101.

7. Lee AL, Goldstein RS, Brooks D. Chronic pain in people with chronic obstructive pulmonary disease: prevalence, clinical and psychological implications. Chronic Obstr Pulm Dis. 2017;4(3):194-203.

8. Bentsen SB, Rustøen T, Miaskowski C. Differences in subjective and objective respiratory parameters in patients with chronic obstructive pulmonary disease with and without pain. Int $\mathrm{J}$ Chron Obstruct Pulmon Dis. 2012;7:137-143.

9. HajGhanbari B, Holsti L, Road JD, Darlene Reid W. Pain in people with chronic obstructive pulmonary disease (COPD). Respir Med. 2012;106(7):998-1005. 
10. HajGhanbari B, Yamabayashi C, Garland R, Road JD, Darlene Reid W. The relationship between pain and comorbid health conditions in people with chronic obstructive pulmonary disease. Cardiopulm Phys Ther J. 2014;25(1):29-35.

11. Bentsen SB, Rustøen T, Miaskowski C. Prevalence and characteristics of pain in patients with chronic obstructive pulmonary disease compared to the Norwegian general population. J Pain. 2011;12(5):539-545.

12. Roberts MH, Mapel DW, Hartry A, Von Worley A, Thomson H. Chronic pain and pain medication use in chronic obstructive pulmonary disease. A cross-sectional study. Ann Am Thorac Soc. 2013;10(4):290-298.

13. Roberts MH, Mapel DW, Thomson HN. The impact of chronic pain on direct medical utilization and costs in chronic obstructive pulmonary disease. Clinicoecon Outcomes Res. 2015; 26(7):173-184

14. Vogelmeier CF, Criner GJ, Martinez FJ, et al. Global Strategy for the Diagnosis, Management, and Prevention of Chronic Obstructive Lung Disease 2017 Report: GOLD Executive Summary. Eur Respir J. 2017;49(3):1700214.

15. Spruit MA, Singh SJ, Garvey C, et al. An official American Thoracic Society/European Respiratory Society statement: key concepts and advances in pulmonary rehabilitation. Am J Respir Crit Care Med. 2013;188(8):e13-e64.

16. Watz H, Waschki B, Meyer T, Magnussen H. Physical activity in patients with COPD. Eur Respir J. 2009;33(2):262-272.

17. Moy ML, Collins RJ, Martinez CH, et al. An internet-mediated pedometer-based program improves health-related quality-of-life domains and daily step counts in COPD: a randomized controlled trial. Chest. 2015;148(1):128-137.

18. Moy ML, Teylan M, Weston NA, Gagnon DR, Garshick E. Daily step count predicts acute exacerbations in a US cohort with COPD. PLoS One. 2013 Apr 4;8(4):e60400. 
19. Wan ES, Kantorowski A, Polak M, et al. Long-term effects of web-based pedometer-mediated intervention on COPD exacerbations. Respir Med. 2020;162:105878.

20. Waschki B, Kirsten A, Holz O, et al. Physical activity is the strongest predictor of all-cause mortality in patients with COPD: a prospective cohort study. Chest. 2011;140(2):331-342.

21. HajGhanbari B, Garland SJ, Road JD, Reid WD. Pain and physical performance in people with COPD. Respir Med. 2013;107(11):1692-1699.

22. Sánchez Castillo S, Smith L, Díaz Suárez A, López Sánchez GF. Associations between physical activity and comorbidities in people with COPD residing in Spain: a cross-sectional analysis. Int J Environ Res Public Health. 2020;17(2):594.

23. Andenæs R, Momyr A, Brekke I. Reporting of pain by people with chronic obstructive pulmonary disease (COPD): comparative results from the HUNT3 population-based survey. BMC Public Health. 2018;18(1):181.

24. Lee AL, Butler SJ, Varadi RG, Goldstein RS, Brooks D. The impact of pulmonary rehabilitation on chronic pain in people with COPD. COPD. 2020;17(2):165-174.

25. Moy ML, Danilack VA, Weston NA, Garshick E. Daily step counts in a US cohort with COPD. Respir Med. 2012;106(7):962-969.

26. Wan ES, Kantorowski A, Homsy D, et al. Promoting physical activity in COPD: Insights from a randomized trial of a web-based intervention and pedometer use. Respir Med. 2017;130:102110.

27. Robinson SA, Cooper JA, Goldstein RL, et al. Results from a multi-site web-based physical activity intervention in COPD: between group and site differences. Oral Presentation at the American Thoracic Society International Conference, 2020. Virtual.

28. Kazis, LE. The Veterans SF-36 Health Status Questionnaire: development and application in the Veterans Health Administration. Medical Outcomes. 2000; 5(1); 1-18. 
29. Kazis LE, Miller DR, Clark JA, et al. Improving the response choices on the veterans SF-36 health survey role functioning scales: results from the Veterans Health Study. J Ambul Care Manage. 2004;27(3):263-280.

30. Wyrwich KW, Fihn SD, Tierney WM, Kroenke K, Babu AN, Wolinsky FD. Clinically important changes in health-related quality of life for patients with chronic obstructive pulmonary disease: an expert consensus panel report. J Gen Intern Med. 2003;18(3):196-202.

31. Moy ML, Janney AW, Nguyen HQ, et al. Use of pedometer and Internet-mediated walking program in patients with chronic obstructive pulmonary disease. J Rehabil Res Dev. 2010;47(5):485-496.

32. Moy ML, Weston NA, Wilson EJ, Hess ML, Richardson CR. A pilot study of an Internet walking program and pedometer in COPD. Respir Med. 2012;106(9):1342-1350.

33. Teylan M, Kantorowski A, Homsy D, Kadri R, Richardson C, Moy M. Physical activity in COPD: Minimal clinically important difference for medical events. Chron Respir Dis. 2019;16.

34. Demeyer H, Louvaris Z, Frei A, et al. Physical activity is increased by a 12 -week semiautomated telecoaching programme in patients with COPD: a multicentre randomised controlled trial. Thorax. 2017;72(5):415-423.

35. ATS Committee on Proficiency Standards for Clinical Pulmonary Function Laboratories. ATS statement: guidelines for the six-minute walk test. Am J Respir Crit Care Med. 2002;166(1):111117.

36. Polkey MI, Spruit MA, Edwards LD, et al. Six-minute-walk test in chronic obstructive pulmonary disease: minimal clinically important difference for death or hospitalization. Am $\mathrm{J}$ Respir Crit Care Med. 2013;187(4):382-386.

37. Redelmeier DA, Bayoumi AM, Goldstein RS, Guyatt GH. Interpreting small differences in functional status: the Six Minute Walk test in chronic lung disease patients. Am J Respir Crit Care Med. 1997;155(4):1278-1282. 
38. Graham BL, Steenbruggen I, Miller MR, et al. Standardization of Spirometry 2019 Update. An Official American Thoracic Society and European Respiratory Society Technical Statement. Am J Respir Crit Care Med. 2019;200(8):e70-e88.

39. Hankinson JL, Odencrantz JR, Fedan KB. Spirometric reference values from a sample of the general U.S. population. Am J Respir Crit Care Med. 1999;159(1):179-187.

40. Bestall JC, Paul EA, Garrod R, Garnham R, Jones PW, Wedzicha JA. Usefulness of the Medical 500 Research Council (MRC) dyspnoea scale as a measure of disability in patients with chronic obstructive pulmonary disease. Thorax. 1999;54(7):581-586.

41. Mahler DA, Witek TJ Jr. The MCID of the transition dyspnea index is a total score of one unit. COPD. 2005;2(1):99-103.

42. McDowell, Ian. Measuring health: a guide to rating scales and questionnaires, third edition. Oxford University Press. 2006;660.

43. Harrison SL, Lee AL, Elliott-Button HL, et al. The role of pain in pulmonary rehabilitation: a qualitative study. Int J Chron Obstruct Pulmon Dis. 2017;12:3289-3299.

44. Geneen LJ, Moore RA, Clarke C, Martin D, Colvin LA, Smith BH. Physical activity and exercise for chronic pain in adults: an overview of Cochrane Reviews. Cochrane Database Syst Rev. 2017;1(1):CD011279.

45. Spruit MA, Watkins ML, Edwards LD, et al. Determinants of poor 6-min walking distance in patients with COPD: the ECLIPSE cohort. Respir Med. 2010;104(6):849-857.

46. Danilack VA, Weston NA, Richardson CR, Mori DL, Moy ML. Reasons persons with COPD do not walk and relationship with daily step count. COPD. 2014;11(3):290-299.

47. Kantorowski A, Wan ES, Homsy D, Kadri R, Richardson CR, Moy ML. Determinants and outcomes of change in physical activity in COPD. ERJ Open Res. 2018;4(3):00054-2018.

48. Chen BI, Hsueh MC, Rutherford R, Park JH, Liao Y. The associations between neighborhood walkability attributes and objectively measured physical activity in older adults. PLoS One. 2019;14(9):e0222268. 
49. Chen YW, HajGhanbari B, Road JD, Coxson HO, Camp PG, Reid WD. Reliability and validity of the Brief Pain Inventory in individuals with chronic obstructive pulmonary disease. Eur J Pain. 2018;22(10):1718-1726.

523 


\section{Figures}

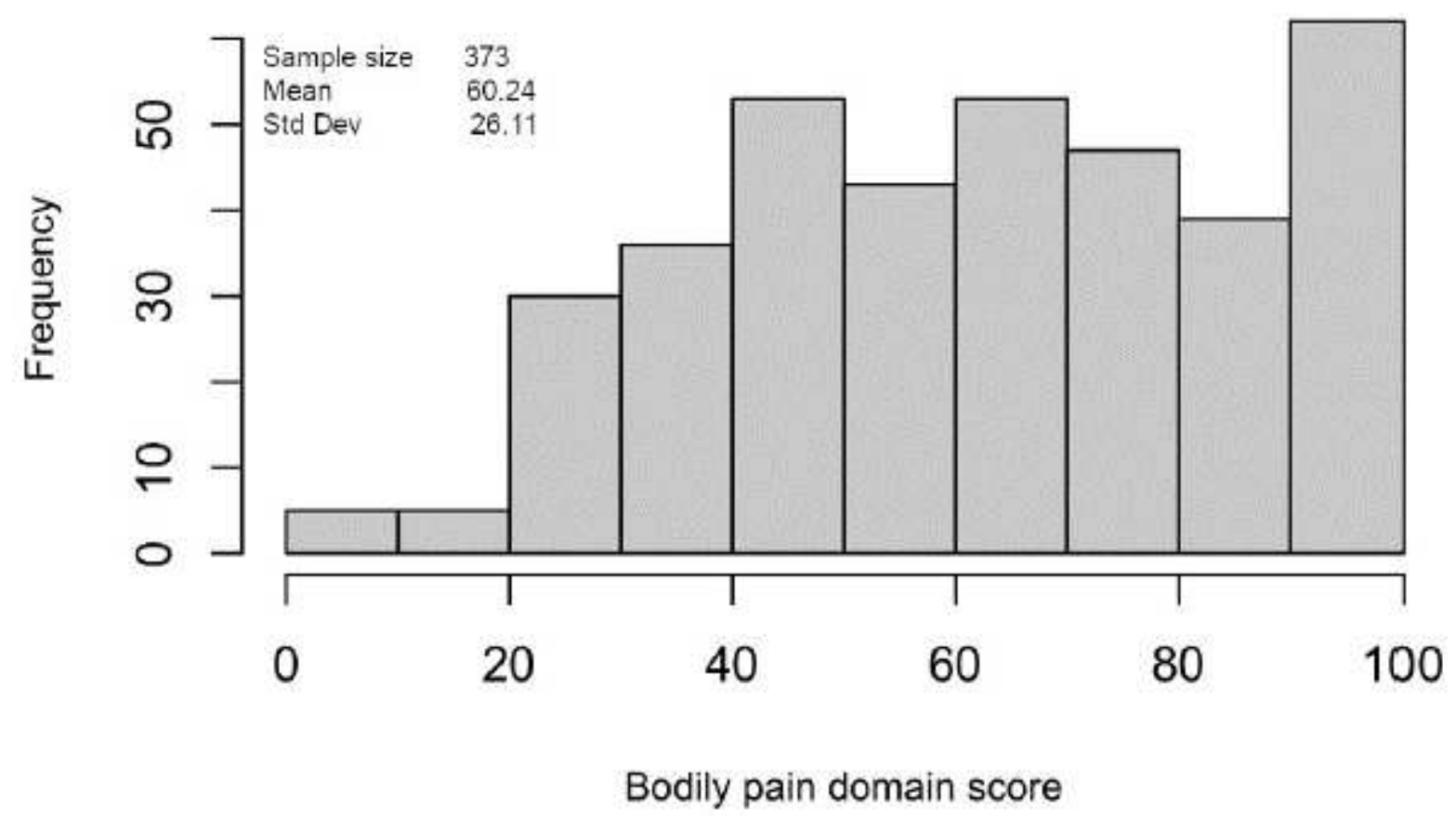

Figure 1

Distribution of bodily pain scores. Histogram demonstrating the distribution of bodily pain scores evaluated with the VR36 survey and assessing symptoms in the four weeks prior to study enrollment. A pain score of ' 100 ' $(n=62)$ corresponds to no pain while a score of ' 0 ' $(n=4)$ indicates very severe pain causing extreme interference with daily activities. 

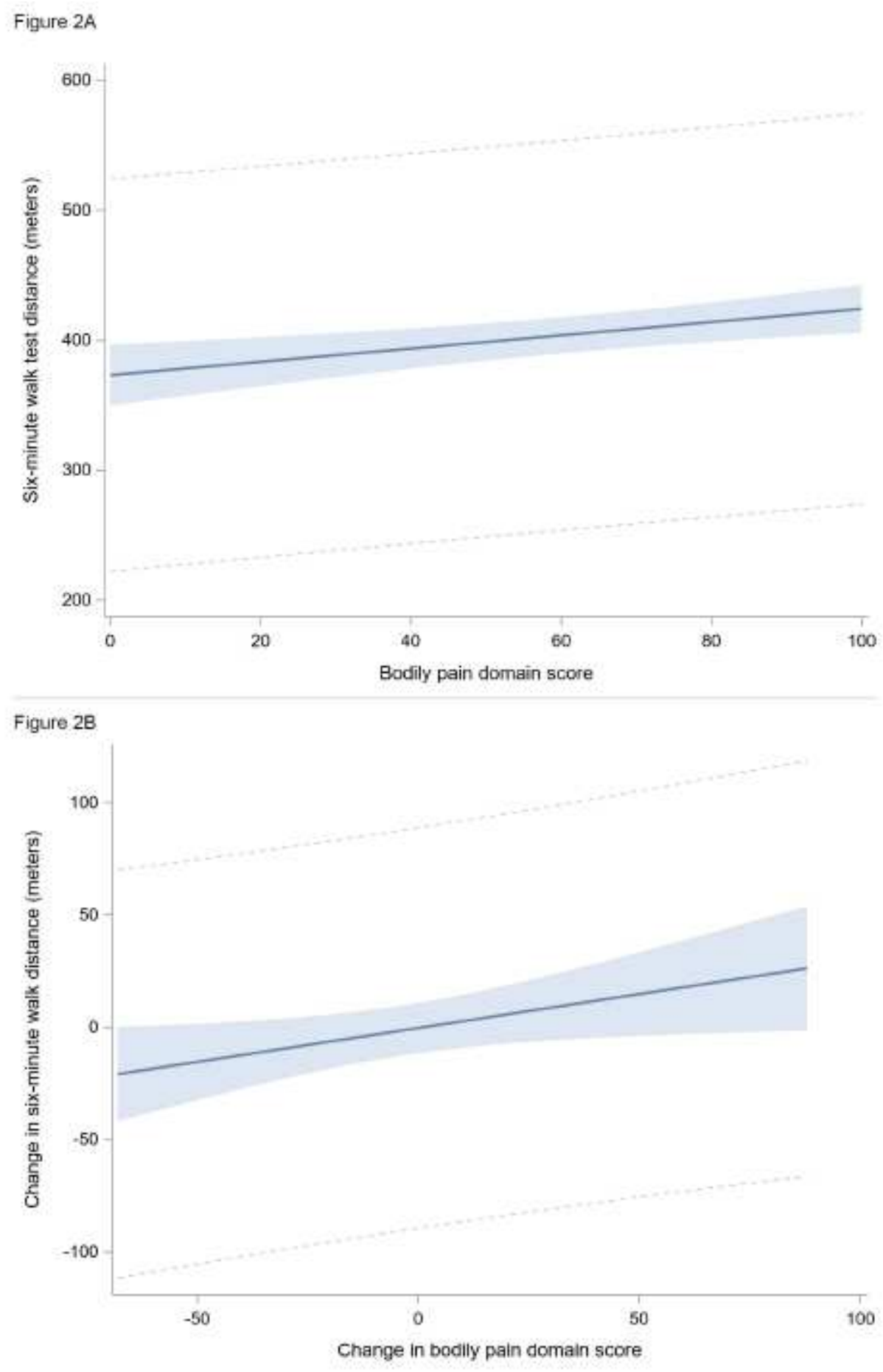

\section{Figure 2}

A,B: Relationships between pain and exercise capacity cross-sectionally (2A) and longitudinally (2B). Generalized multivariate linear regression models with $95 \%$ confidence interval adjusted for BMI, percent predicted FEV1, and cohort. A bodily pain score of ' 100 ' represents no pain while a score of ' 0 ' represents severe pain causing extreme interference. A change in pain score $>0$ indicates improved pain. Figure $2 \mathrm{~A}$ represents results of a model evaluating the cross-sectional relationship between bodily pain score and $6 \mathrm{MWT}$ distance both measured at baseline. Figure 2B represents results of a model evaluating the longitudinal relationship between the change in BP and 6MWT. 